\title{
UV Spectrophotometric method for quantitative determination of Agomelatine in coated tablets
}

\author{
Fábio de Souza Barbosa ${ }^{a^{*}}$, Vanise Coty Rodrigues ${ }^{\mathrm{b}}$, Nadia M. Volpato ${ }^{\mathrm{a}}$, \\ Elfrides E. S. Schapoval ${ }^{a}$, Martin Steppe ${ }^{a}$, Cássia V. Garcia ${ }^{a}$, \\ Andreas S. L. Mendez \\ ${ }^{a}$ Programa de Pós-graduação em Ciências Farmacêuticas, Universidade Federal do Rio Grande do Sul, Av. Ipiranga \\ 2752, CEP 90610-000, Porto Alegre - RS, Brasil \\ ${ }^{b}$ Faculdade de Farmácia, Universidade Federal do Rio Grande do Sul, Av. Ipiranga 2752, CEP 90610-000, Porto \\ Alegre - RS, Brasil
}

Corresponding author e-mail: fabiodsbarbosa@yahoo.com

UV spectrophotometry is an analytical technique used routinely for qualitative and quantitative assay due the low cost and reliability during analysis. In this work, it was validated a quantitative UV method for determination of agomelatine in coated tablets. The parameters specificity, linearity, precision, accuracy and robustness were evaluated according to official guidelines. Methanol was selected as solvent and the maximum wavelength for drug analysis was $230 \mathrm{~nm}$. The purposed assay showed to be specific and the linearity was proved in a range of $0.5-2.5 \mu \mathrm{g} / \mathrm{mL}$. The RSD values obtained during precision assay (inter-day RSD $=1.75 \%$ ) indicated the method reproducibility, and the accuracy testing showed good results from recovery test. Robustness assay was complementary and showed that the purposed method is adequate for drug quantitation in commercial samples, being a reliable alternative to chromatographic assay.

Keywords: agomelatine; UV spectrophotometry; validation; quantitation.

\section{Introduction}

Agomelatine is the first nonmonoaminergic antidepressant drug approved for the treatment of major depressive disorder. This new drug acts as agonist of melatonergic $\mathrm{MT}_{1} / \mathrm{MT}_{2}$ receptors as well as an antagonist of serotonergic $5-\mathrm{HT}_{2} \mathrm{C}$ receptors, resulting in an increased extracellular release of noradrenaline and dopamine in the frontal cortex. This unique mechanism of action confers to agomelatine the ability to regulate circadian rhythms (1-3). Clinical efficacy studies have shown that agomelatine has similar action to other antidepressant drugs, such as venlafaxine, paroxetine and sertraline (4-6).

Chemically analogous to melatonin, agomelatine ((N-[2-(7-methoxy-1naphthyl)ethyl]acetamide) (Figure 1) is characterized as a white crystalline powder, being practically insoluble in water and very soluble in organic solvents such as ethanol, methanol and dichloromethane $(3,7)$. Developed by the Servier Laboratories Ltd (Neuilly, France) industry, agomelatine was approved for clinical use in Brazil since 2009 and is marketed as coated tablets (Valdoxan ${ }^{\circledR}$ $25 \mathrm{mg})(8)$.

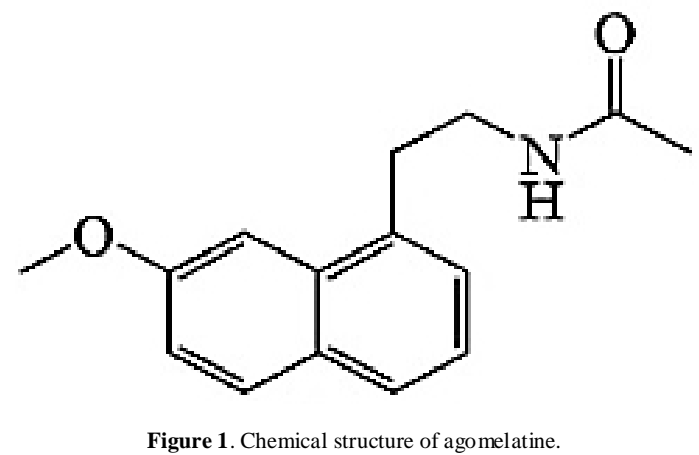


The scientific literature reports some analytical assays applied to agomelatine in different matrices. Among them, we highlighted chromatographic methods for its determination in biological fluids (9), analysis of related impurities (10), and method for quantitation in pharmaceuticals (11). Being an alternative to chromatographic assay, in the present study we aimed to develop an UV spectrophotometric method for quantitative analysis of agomelatine in commercial sample, applying validation protocols.

\section{Experimental}

\section{Chemicals and apparatus}

Agomelatine reference standard (99.91\%) was purchased from BOC Sciences (CA, USA). Valdoxan® (Servier Laboratories Ltd.) containing $25 \mathrm{mg}$ of agomelatine were purchased in the local market. The excipients used for the placebo solution (lactose monohydrate, starch, povidone, sodium starch glycolate, stearic acid, magnesium stearate, anhydrous colloidal silica, hypromellose, yellow iron oxide, glycerol, macrogol, magnesium stearate, titanium dioxide) were acquired from different suppliers. Methanol and acetonitrile UV-HPLC grade were purchased from Merck (Darmstadt, Germany).

The UV spectrophotometric method was performed on an UV-1800 UV/Vis Spectrophotometer Shimadzu (Kyoto, Japan) using $1 \mathrm{~cm}$ quartz cells. For the analysis, the wavelength was set at $230 \mathrm{~nm}$ and the results were processed in UVProbe software.

\section{Standard and sample preparation}

A stock solution of agomelatine standard reference $100 \mu \mathrm{g} / \mathrm{mL}$ was prepared. For it, $5 \mathrm{mg}$ of agomelatine were weighted and transferred to $50 \mathrm{~mL}$ volumetric flask, being solubilized in methanol. From this solution, different concentrations of analytical solutions were obtained by successive dilutions.

For sample solutions, twenty tablets were weighed and crushed to a fine powder. An accurately weighed amount of tablet powder equivalent to $10 \mathrm{mg}$ of agomelatine was transferred to a $100 \mathrm{~mL}$ volumetric flask with $70 \mathrm{~mL}$ of methanol and sonicated for $45 \mathrm{~min}$, followed by adding the same solvent to make up the volume. After sonication, the solutions were filtered on quantitative filter paper and diluted at the working concentrations, using the same solvent.

\section{Validation}

The UV-spectrophotometry method was validated according to official validation guidelines (12,13). The parameters studied were specificity, linearity, precision, accuracy and robustness.

\section{Specificity}

The specificity was assessed by testing analytical interferences from excipients. This analytical parameter was determined by comparing ultraviolet absorption spectra obtained from agomelatine standard solution, sample solution and placebo. The spectra were obtained in the range of 200 to $400 \mathrm{~nm}$, and the overlap of absorption bands was evaluated. Through spectral scans, it was also possible to determine the absorption wavelength maxima of agomelatine when solubilized in methanol.

\section{Linearity}

The method linearity was studied by performing three independent analytical curves, within five concentration levels ranging 0.5 $2.5 \mu \mathrm{g} / \mathrm{mL}$. Standard plots (concentration versus absorbance) were constructed, and linearity was evaluated statistically by linear regression analysis through least square method and applying ANOVA (analysis of variance).

\section{Precision}

Precision was determined by repeatability (intraday) and intermediate precision (interday). Repeatability was evaluated by assaying six samples solutions at $2.0 \mu \mathrm{g} / \mathrm{mL}$ during the same day, and the intermediate precision was studied by comparing the assays 
on three different days. The analyses were done in triplicate and results were expressed as the relative standard deviation (RSD) of the analytical measurements. Samples were prepared as previously described.

\section{Accuracy}

Accuracy was determined based on the recovery of known amounts of agomelatine reference standard added to samples at the levels of 5, 10 and $20 \%$ of the sample concentration $(2.0 \mu \mathrm{g} / \mathrm{mL})$. The accuracy was calculated as the percentage of the drug recovered and also expressed as the relative standard deviation (RSD) between the measurements.

\section{Robustness}

Robustness was determined by through small modifications in the established analytical conditions. The experiments were conducted by testing two different manufacturers for the solvent (methanol): Merck (Darmstadt, Germany) and Vetec (São Paulo, Brazil); and also through small variations in the selected wavelength for analysis (228 $\mathrm{nm}$ and $232 \mathrm{~nm})$.

\section{Results and Discussion}

UV-visible spectrophotometry is an analytical technique widely used in the quality control of drugs, being present in official monographs, for identification and quantitation (14). This technique is highlighted in the scientific literature, in which several reports are focused in drug quantitation with a performance equivalent to HPLC, i.e. assaying fluoxetine (15), sulfasalazine (16), paliperidone (17) and posaconazole (18). In these studies, there is no significant difference between the results obtained by both techniques.

Although there are limitations regarding specificity, the UV-spectroscopy presents some advantages when compared to chromatographic methods, such as faster analysis, low operating costs and low generation of waste. An alternative for improve the specificity and sensitivity of the technique is to perform UV derivative spectrophotometric method (19). This method consists in calculating mathematically the derivative of the obtained spectra, improving resolution and reducing noise and matrix effects $(19,20)$. These advantages are determinants for new analytical investigations with quantitative focus.

In the present study, the method development started with preliminary tests, applied to establish better conditions for analyses, studying the solvents for sample extraction, the concentration for analyses and the Kmax for quantification. In order to determine the best wavelength for analysis, scans were performed in the range of 200 to 400 $\mathrm{nm}$, whose results indicated the maximum absorbance at $230 \mathrm{~nm}$.

Due the low drug solubility in water and based on studies already published in the literature, we selected acetonitrile and methanol as solvents, evaluating the drug extraction in different times by ultrasonic bath. Samples submitted to the extraction with acetonitrile presented turbidity and resistance to filtration, and the results illustrated a higher variation in the drug content after extraction. Using methanol, the extraction profile is presented in Table 1.

\begin{tabular}{|c|c|c|c|}
\hline Time $(\min )$ & Amount (\%) & $\begin{array}{c}\text { Mean amount } \\
(\%)\end{array}$ & RSD \\
\hline \multirow{3}{*}{15} & 96.87 & \multirow{3}{*}{95,40} & \multirow{3}{*}{1.92} \\
\hline & 93.34 & & \\
\hline & 96.00 & & \\
\hline \multirow{3}{*}{30} & 95.81 & \multirow{3}{*}{98,45} & \multirow{3}{*}{2.33} \\
\hline & 99.62 & & \\
\hline & 99.93 & & \\
\hline \multirow{3}{*}{45} & 102.00 & \multirow{3}{*}{101,88} & \multirow{3}{*}{0.16} \\
\hline & 101.75 & & \\
\hline & 101.90 & & \\
\hline
\end{tabular}

Representative UV spectra of agomelatine standard reference, sample solution and placebo are presented in Figure 2, at the 
wavelength selected for analysis $(230 \mathrm{~nm})$, it is possible to observe a small absorbance from placebo solution, less than $2 \%$ of the maximum absorbance from agomelatine reference standard. Experimentally, this performance indicates that there is no interference in the analysis. The method is specific for the intended analysis.

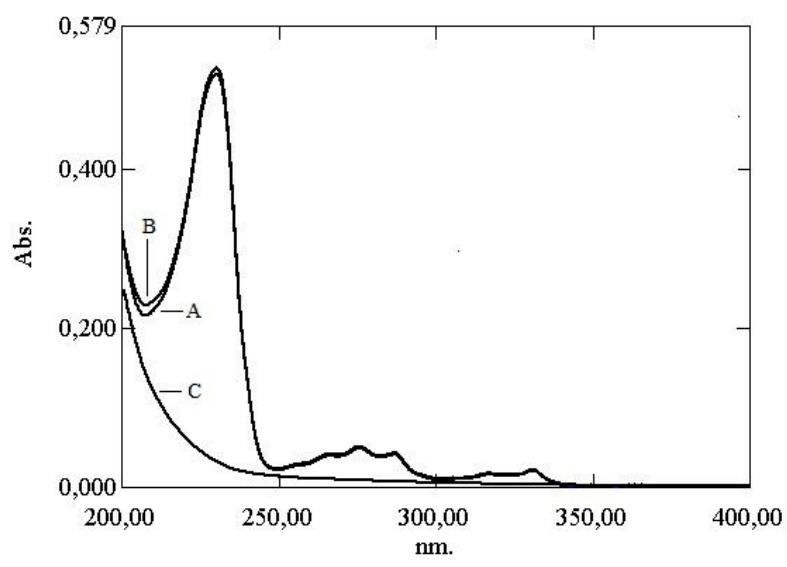

Figure 2 UV spectrum of agomelatine reference substance (A), sample solution (B) and placebo solution (C), prepared in methanol at a final concentration of 2.0 $\mu \mathrm{g} / \mathrm{mL}$.

range of 0.5 to $2.5 \mu \mathrm{g} / \mathrm{mL}$. The regression equation obtained was $\mathrm{y}=0.3225 \mathrm{x}-0.0044$ and the correlation coefficient was $r=0.9998$. Statistical analysis by ANOVA confirmed the linear regression $\left(\mathrm{F}_{\text {calculated }}=4777>\mathrm{F}_{\text {critical }}=\right.$ 4.96; $\mathrm{p}=0.05)$ and shows that there is no deviation from linearity $\left(\mathrm{F}_{\text {calculated }}=2.0<\mathrm{F}_{\text {critical }}\right.$ $=3.71 ; \mathrm{p}=0.05)$. For the intercept, the statistical p-value obtained (0.179) indicated that there is no statistical difference from zero point in the calibration range worked at the $95 \%$ confidence level. The residual plots demonstrated the absence of outliers, and the Cochran C-test indicated homoscedasticity of residuals variance $\left(\mathrm{C}_{\text {calculated }}=0.570<\mathrm{C}_{\text {critical }}=\right.$ 0.684). The results obtained from linearity parameter study are summarized in Table 2 .

Table 2. Linearity results obtained from validation of UV spectrophotometric method for quantitative determination of agomelatine in coated tablets.

\begin{tabular}{ll}
\hline Parameter & Results \\
\hline Calibration range & $0.5-2.5 \mu \mathrm{g} / \mathrm{mL}$ \\
Regression equation & $\mathrm{y}=0.3225 \mathrm{x}-0.0044$ \\
Slope \pm standard deviation & $0.3225 \pm 0.0070$ \\
Intercept \pm standard deviation & $0.0044 \pm 0.0037$ \\
Correlation coefficient $(\mathrm{r})$ & 0.9998 \\
\hline
\end{tabular}

As illustrated in Table 3, the quantitative values obtained from precision study showed repeatability (intraday assay) with low values of $\mathrm{RSD}$, ranging between 0.58 to 2.66 . The intermediate precision was determined by performance of sequential analysis on three different days. These results were confirmatory for the expected reproducibility in this experimental purpose. Accuracy was studied by applying the recovery test, which was performed by adding the reference standard to the sample solution and analyzing the total drug content in the final matrix, expressing the results as percentage of drug recovered. As described in Table 4, the proposed method by UV spectrophotometry showed to be accurate for agomelatine determination, presenting an average recovery between $99.11 \%$ and $103.97 \%$, being considered satisfactory. The method was also shown to be robust, considering the experimental modifications made in order to evaluate this parameter. Testing different wavelengths of analysis and different manufacturers for the solvent, the drug content was not influenced, demonstrating that the method support little variations during analysis.

Table 3 Results obtained for repeatability and intermediate precision parameters, studied during validation of UV method for quantitation of agomelatine in coated tablets.

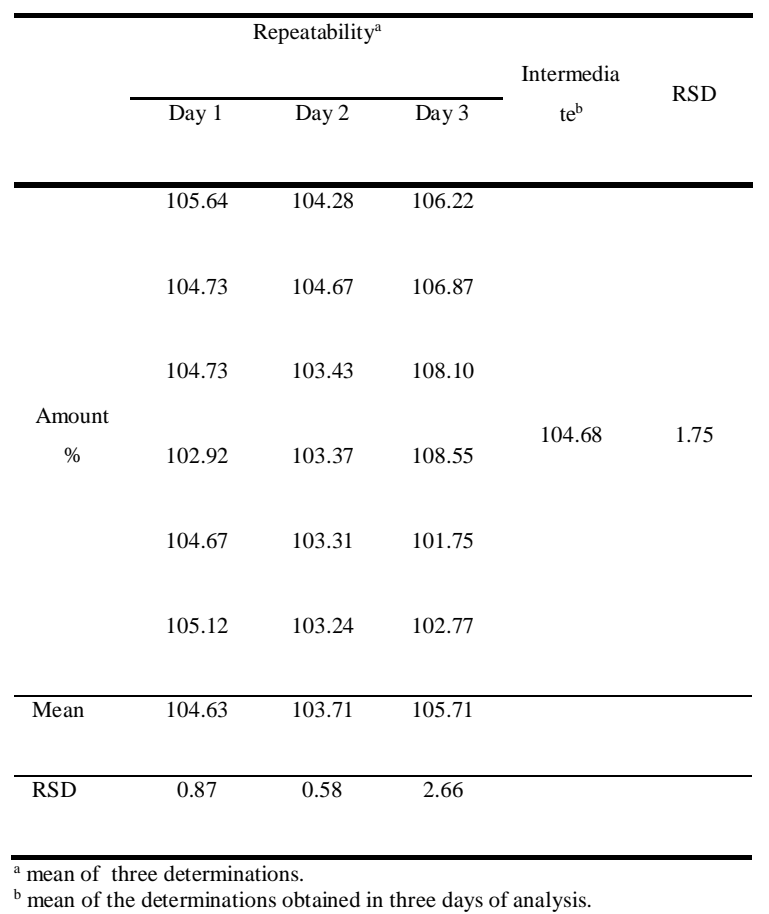


Table 4 Results obtained from recovery testing studied for validation of UV method for quantitation of agomelatine in coated tablets.

\begin{tabular}{|c|c|c|c|c|}
\hline & \multicolumn{4}{|c|}{ Concentration $(\mu \mathrm{g} / \mathrm{mL})$} \\
\hline & $\begin{array}{c}\text { Concentration } \\
\text { added } \\
(\mu \mathrm{g} / \mathrm{mL})\end{array}$ & $\begin{array}{c}\text { Concentration } \\
\text { found } \\
(\mu \mathrm{g} / \mathrm{mL})\end{array}$ & $\begin{array}{c}\text { Recovery }^{\mathrm{a}} \\
(\%)\end{array}$ & RSD \\
\hline \multirow{3}{*}{ Level 1} & \multirow{3}{*}{0.10} & 0.104 & \multirow{3}{*}{103.97} & \multirow{3}{*}{0.79} \\
\hline & & 0.102 & & \\
\hline & & 0.104 & & \\
\hline \multirow{3}{*}{ Level 2} & \multirow{3}{*}{0.20} & 0.197 & \multirow{3}{*}{99.11} & \multirow{3}{*}{0.38} \\
\hline & & 0.199 & & \\
\hline & & 0.197 & & \\
\hline \multirow{3}{*}{ Level 3} & \multirow{3}{*}{0.40} & 0.411 & & \multirow{3}{*}{0,89} \\
\hline & & 0.401 & 102.06 & \\
\hline & & 0.402 & & \\
\hline
\end{tabular}

\section{Conclusions}

A simple, fast and reliable UV spectrophotometric method for quantitative analysis of agomelatine in coated tablets was developed and validated. The proposed method presented adequate performance for the intended analysis, demonstrating to be sensitive, precise and accurate. In addition, this UV method represents a real alternative to chromatographic assay, considering the routine of quality control laboratories and more simple protocols focused on drug content determination batch to batch.

\section{References}

1. Racagni G, Riva MA, Molteni R, Musazzi L, Calabrese F, Popoli M, Tardito D. Mode of action of agomelatine: Synergy between melatonergic and 5-HT2C receptors. World J Biol Psychiatry. 2011; 12: 574 - 587.

2. Kennedy SH, Rizvi SJ. Agomelatine in the treatment of major depressive disorder. CNS Drugs. 2010; 24: 479-499.

3. Millan MJ, Gobert A, Lejene F, Dekeyne A, Newman-Tancredi A, Pasteau V, Rivet JM, Cussac D. The Novel Melatonin Agonist Agomelatine (S20098) Is an Antagonist at 5-Hydroxytryptamine2C
Receptors, Blockade of Which Enhances the Activity of Frontocortical Dopaminergic and Adrenergic Pathways. J Pharmacol Exp Ther. 2003: 306: 954-964.

4. Demyttenaere K. Agomelatine: A narrative review. Eur Neuropsychopharmacol. 2011; $21: 703-709$.

5. Hale A, Corralb RM, Mencaccic C, Ruizd JS, Severoe CA, Gentilf V. Superior antidepressant efficacy results of agomelatine versus fluoxetine in severe MDD patients: a randomized, double-blind study. Int Clin Psychopharmacol. 2010; 25: 305.

6. Kennedy SH, Rizvi S, Fulton, K, Rasmussen JJ. A Double-Blind Comparison of Sexual Functioning, Antidepressant Efficacy, and Tolerability Between Agomelatine and Venlafaxine XR. Clin Psychopharmacol. 2008; 28: $329-333$.

7. Salaman P, Ramon C, Tesson N, Lydia CR, Marçal CC. European Patent Application. (EP 2551257 A1). 2013.

8. BRASIL. Agência Nacional de Vigilância Sanitária. Resolução - RDC n ${ }^{0}$ 7, de 26 de fevereiro de 2009.

9. Patil SR, Nerurkar KK, Kalamkar AM, Pukale V, Mangaonkrc KV, Pingalec SGJ. Validated LC-MS/MS method for quantification of agomelatine in human plasma and its application in a pharmacokinetic study. J Mass Spectrom. 2012; 47: 23 - 28.

10. Liu Y, Chen L, Ji Y. Quantification and structural elucidation of potential impurities in agomelatine active pharmaceutical ingredient. J Pharm Biomed Anal. 2013; 81: 193 - 201.

11. Sagar PV, Shivani P, Sushma E, Rani SS. Stability indicating RP-HPLC method for estimation of agomelatine in tablete dosage form. Int J Pharm Biol Sci. 2015; 5: 74 - 81 .

12. BRASIL. Agência Nacional de Vigilância Sanitária. Resolução - RE n ${ }^{\circ} 166$, de 24 de julho de 2017. 
13. ICH. Harmonised Tripartite Guideline. Validation of Analytical methods text and methodology Q2(R1). In: Internacional Conference on Harmonization of Technical Requirenments for Registration of Pharmaceuticals for Human Use, 2005

14. BRASIL. Farmacopéia Brasileira. $5^{\mathrm{a}}$ ed. Brasília: Agência Nacional de Vigilância Sanitária. 2010.

15. Fregonezi-Nery MM, Baracat MM, Casagrande R, Machado HT, Miglioranza B, Gianotto EAS. Validação de métodos para determinação de fluoxetina em cápsulas. Quim Nova. 2008; 31: 1665 - 1669.

16. Costa MAB, Ricci-Júnior E, Santos EP, Mansur CRE, Campos VEB. Desenvolvimento e validação de método analítico para a determinação de sulfassalazina em suspensão oral: comparação do método espectrofotométrico e de cromatografia líquida de alta eficiência (CLAE). Quim Nova. 2012; 35: $808-813$.

17. Mendez ASL, Cassol JPE, Camargo VB, Malesuik MD, Garcia CV. Quantitative Determination of Paliperidone in OROS ${ }^{\circledR}$ Tablets by Derivative Spectrophotometric Method - Application in Extraction and Comparison to HPLC. Curr Anal Chem. 2014; 10: $158-165$.

18. Bitencourt AS, Oliveira SS, Mendez ASL, Garcia CV. UV spectrophotometric method for determination of posaconazole: comparison to HPLC. Rev Ciênc Farm Básica Apl. 2015; 36: 491 - 495.

19. Ojeda C, Rojas F. Recent developments in derivative ultraviolet/visible absorption spectrophotometry. Anal Chim Acta. 2004; 518:1 - 24.

20. Rojas F, Ojeda C. Recent development in derivative ultraviolet/visible absorption spectrophotometry: 2004-2008: A review. Anal Chim Acta. 2009; 635: 22 - 44. 